\title{
The structure of work environments in psychiatric rehabilitation
}

\author{
Therapeutic alternatives to the industrial workshop
}

Nigel Mills, Senior Psychologist, Department of Psychology, Fulbourn Hospital,
Cambridge CB1 5EF

There is now an extensive literature describing the value of work for people with a psychiatric disability (Shepherd, 1989; Bennett, 1970; Wing \& Brown, 1970; Pilling, 1988). Apart from financial gain the benefits of work can include social contacts and support; social status and identity; 'normal' nonpatient roles; a means of structuring and occupying one's time; a sense of personal achievement and mastery and a criterion of recovery from illness (Shepherd, 1984). However, for many people with a long-term psychiatric disability the range of opportunity for work is often very limited, usually consisting of subcontract packing or assembly work. The provision of this repetitive and simple work satisfies a basic occupational need. However to a large extent it neglects the fulfilment of broader psychological and social needs. People with a vulnerability to experience periods of major mental disorder usually have more than just an occupational need; they also need to be in an environment which can provide the conditions that will actively assist in the promotion of a state of positive mental health.

The provision of such conditions is particularly crucial for psychiatric patients in the community who may have very few, if any, other sources of social support (Wing \& Brown, 1970). A new long-term patient in the community, for example a young male with schizophrenia, will typically experience not only primary psychological deficits (poor concentration, slowness, etc) but will also experience a range of secondary social and psychological consequences including impaired social interaction skills; low selfesteem and loss of confidence in his own abilities (Strauss et al, 1989). He will also typically have a disrupted work history from his early teens and thus may not have had an opportunity to develop any specific skills which could be utilised in his search for open employment. Thus for a young male patient prone to periods of schizophrenia, traditional workshop occupational activity may structure his day but it does not maximise the opportunity for him to reduce his secondary social and psychological difficulties.
The effect of different work environments on mental health has recently been the subject of a comprehensive review by Warr (1987). Warr has developed a 'vitamin' model which describes nine principal categories of environmental attributes. He suggests that these categories bear a close relationship to the degree of positive mental health present in the worker.

The categories are as follows: opportunity for control; opportunity for skill use; externally generated goals; variety; environmental clarity; availability of money; physical security; opportunity for interpersonal contact; and valued social position.

The vitamin analogy is developed to describe two different modes of operation. A Vitamin AD relationship ('additional decrement') where large doses may be toxic is distinguished from a CE ("constant effect') relationship where once a certain minimum level is reached no further changes are noted. Warr suggests that the constant effect pattern applies to three of the environmental features (money, physical security and valued social position) with the remainder being of the additional decrement kind.

Warr's model has been derived largely retrospectively, i.e. from looking at work environments already in existence. However, it would appear to be of considerable value prospectively. If one is considering designing a work environment where the improved mental health of the workers is the primary aim one could take the above environmental attributes as a basis for both the choice of the nature of the task and the design of the social structure within which the task is arranged.

I would like to describe two work rehabilitation projects which were initiated as a deliberate attempt to create conditions favourable for the improvement of positive mental health in psychiatric patients. These two projects will then be discussed in terms of some of Warr's key categories.

The two projects both evolved out of traditional psychiatric services; the first employing patients from a rehabilitation work unit and the second employing patients who attended a day clinic in the community. 


\section{Project 1: REDHILL RECYCLERS: Wingfield Work Unit, Redhill, Surrey}

This project was set up by the author in the autumn of 1988 to provide a co-operative venture in glass bottle recycling. Ldcal businesses and private households were encouraged to collect their empty glass bottles in large plastic barrels. The full barrels were then collected on a weekly basis in a transit van and delivered to a collection depot where they were weighed and a docket received for the total weight. These dockets were then collated into a monthly invoice to be sent to the glass recycling company.

This project required the following personnel: two drivers, four 'mates', one book-keeper, and one petty-cash keeper. All personnel were drawn from patients who had recovered from the acute phase of their psychiatric disorder and were now attending a rehabilitative work unit. Weekly meetings were held to discuss the progress of the project and ongoing problems. Patients at the rehabilitation unit generally competed to be involved in the project and visibly 'came alive' when involved in the project compared to their normal assembly work designation.

\section{Project 2: CAMBRIDGE DAY CLINIC CANTEEN PROJECT}

This project was partly inspired by the Fountain House model (Beard, Propst \& Malamud, 1982). The aim was to create a 'canteen' that could provide food for the attenders and staff of a day clinic for the long term psychiatrically disabled. Workers were drawn from attenders at the day clinic and were encouraged to take part in decision making concerning content of the menu, prices and frequency of opening. This project required food preparers, servers, washer-upers, a book-keeper and a shopper.

The alternative available for this group of clients was to sit in a smoke filled 'drop-in' room and listen to the radio.

The nature of the work provided in these projects is obviously quite different; however the similarity between the projects lies in their attempt to create conditions that favour the development of the healthy psychological functioning of the individual.

There are not at the present time clear quantitative standards on which to compare different work environments in terms of their effect on mental health. I would, however, like to consider some issues relating to the operation of four particular categories described by Warr which appear to be of specific relevance within the context of psychiatric rehabilitation.

\section{Warr's category 1: OPPORTUNITY FOR CONTROL}

Both of the projects were concerned that the workers' perception of themselves should not remain rooted in the concept of a passive patient accepting whatever work was placed in front of him. The aim was rather to create a structure within which the patient would be encouraged to see himself as a valuable worker who has a considerable degree of control over the task before him.

This process does not happen easily. I sat in many workers' meetings at the inception of Redhill Recyclers faced with people apparently quite reluctant to enter into any form of interaction. Perhaps one of the significant points in the initiation of participatory decision making and the workers beginning to avail themselves of the opportunity for control was at the beginning of winter. After a morning of handling snow-covered glass bottles one worker suggested buying some gloves. The book-keeper agreed that there were sufficient funds to purchase gloves; one of the workers claimed to know a shop that sold gloves and on the next bottle collection the driver stopped to buy them. The focus had shifted from mere occupation to involvement in a cognitive process that included the worker as an active agent. A similar process occurred in the design of a leaflet advertising the scheme; in the purchase of a first aid kit and protective goggles; in the repair of the van; in the planning of further pick up points; in the thinking of a name for the scheme; in sign-writing the name on the side of the van, etc.

The constant difficulty faced by staff in such a project is to stop themselves making decisions for the workers and to stop themselves carrying out tasks which appear to be crying out to be done. It is all too easy to get immersed in making the project an operational success and forget that the reason for its inception was to maximise the opportunities for the workers to take control themselves. However, from Warr's notion of 'additional decrement' one would also predict that too much opportunity for control will lead to a deterioration in mental health.

The Cambridge Canteen Project at its inception utilised one particularly able worker, Mrs L, to take on a variety of controlling functions. Mrs L planned the menu, was responsible for the hygiene of the kitchen and she also supervised the other workers. After only a couple of weeks Mrs L began to experience increasingly painful bouts of stress related arthritis and had to withdraw from the project. This arrangement, as well as giving too much control to one particular worker, also reduced the opportunities for control for the other workers. In the light of this experience it was decided to distribute control more equally between the workers by holding a weekly 'planning meeting' which was open to all 
workers to give suggestions as to the content of the menu, to distribute tasks and to consider issues relating to the long term direction of the project. The adoption of a cooperative business structure gave each worker an element of control over the nature of their work but did not overburden any one worker.

\section{Warr's category 3: EXTERNALLY GENERATED GOALS}

A requirement of attendance at a traditional rehabilitation workshop does represent an externally generated goal in that the worker knows that he/she is expected to turn up at a certain time on a certain day. A non attendance means a mark of absence and the hacksaw components stay in their boxes. However the requirement of attendance represents a more powerful externally generated goal when it is in the context of a cooperative work project. If a worker has a unique role and the role of each worker is interdependent then the 'traction' of the task is considerably increased.

The traction represented by the task of being the shopper for the Cambridge canteen project was of particular therapeutic benefit for one lady, Mrs T. Before her involvement in the canteen project Mrs T had found it hard to get herself out of bed to attend the day clinic 'drop in' or a women's goal setting group of which she was a member. The role of shopper meant that if she did not turn up the food preparers would be left with nothing to prepare, potential customers would go hungry and the project would quickly lose credibility. The power of this externally generated goal was sufficient to lift Mrs T from her normal state of lethargy. Through some gentle prompting and inevitably some very last minute shopping Mrs $\mathrm{T}$ became increasingly reliable and also began to be more active on days when she wasn't shopping. For Mrs $T$ the traction of the externally generated goal thus improved her state of mental health.

However from Warr's notion of 'additional decrement' one would predict that if the traction exceeded a certain threshold level one would see a deterioration in mental health. The early operation of Redhill Recyclers descriptively illustrates this pattern. Mr $\mathrm{J}$ had driven Ford Transits in a previous employment and he was therefore given the role of driver of the bottle collecting van. If $\mathrm{Mr} J$ did not turn up he caused a chain reaction of problems, bottles did not get collected, businesses telephoned the unit to complain that their bins were overflowing, the two non-driving work mates were prevented from working, etc. Initially $\mathrm{Mr} \mathrm{J}$ relished his new-found importance and appeared to show a visible increase in his self-confidence to the extent that he began to talk about obtaining open employment as a driver. However after a few weeks $\mathrm{Mr} \mathbf{J}$ began to show signs of stress, he became irritable with the other workers, turned up late and then began to miss whole days. The traction of the externally generated goal had become too great, he had no opportunity to escape from the demands of the task. The solution was again to create more of a co-operative structure whereby other workers could be encouraged to share the role of driver.

\section{Warr's category 8: OPPORTUNITY FOR INTERPERSONAL CONTACT}

Most workshop based tasks involve the worker acting in isolation. He is usually surrounded by other workers but the nature of the work does not require that he interact with them in any way that is essential to the completion of the task. The nature of the work for Redhill Recyclers and the Cambridge Canteen project demands social interaction in at least two ways: firstly the specific operations concerned with the completion of the task are of an interactional nature, and secondly involvement in the general planning of the project is done on a group discussion and decision-making basis.

In Redhill Recyclers the task of collecting the barrels full of bottles requires three people who have to help each other in the lifting and arrangement of the barrels in the van. This cannot be achieved without verbal interaction. Secondly each worker is required to attend a weekly planning meeting where the progress of the project is reviewed. This meeting involves the workers in deciding the rota for the next week, suggesting improvements to certain operational de-tails and reviewing the financial status of the project. Similarly the Cambridge Canteen Project demands interaction and cooperation at the task level of preparation and serving food and at the planning level of organising next week's menu, the work rota and reviewing the financial status of the project. Thus social interaction is an inherent part of each worker's role.

Warr suggests that the value of interpersonal contact again operates on an 'additional decrement' basis so that once an individual's threshold level of interpersonal contact has been exceeded one would predict a deterioration in the mental health of that worker. Warr further suggests that the quality of the interpersonal contact is particularly important in determining an individual's threshold level. The notion of support versus hostility is seen as a particularly important dimension (La Rocco \& Jones, 1978). The notion of hostility in the context of expressed emotion is, of course, now an established factor in determining the relapse likelihood of people suffering from schizophrenia (Leff \& Vaughn, 1985). When considering schizophrenia and other major psychiatric disorders one is also faced with a large degree of 
variation within the same individual in terms of tolerance for interpersonal contact. Both of the above projects therefore had to adopt a flexible approach to the inclusion of workers in situations that required a high degree of interaction.

\section{Warr's category 9: VALUED SOCIAL POSITION}

Traditional rehabilitation work does not lend itself to encouraging a sense of a valued social position. The nature of the work involved in Redhill Recyclers and the Cambridge Canteen Project is not particularly skilled and, with the exception of book-keeping and shopping, can be generally mastered by most clients within one or two sessions. This is not to say that the work is not seen as valuable. The preparation and distribution of food is associated with the satisfaction of a very basic need. Furthermore the canteen project has a high profile role in the organisation of the day clinic and is recognised both within the clinic and outside as being an important innovative project. The collection of glass bottles for recycling is one step removed from the satisfaction of a basic need. However, with a recent heightened awareness as to environmental issues the project was seen as 'worthwhile' in a broad global context both by the local community and by those within the project.

Warr suggests that valued social position does not work on the basis of 'additional decrement' but rather in terms of 'constant effect' i.e. mental health will improve with the degree of valued social position up to a certain threshold level, further increases in the degree of valued social position will then have a constant effect.

\section{Comment}

The themes which have come out of the above descriptions appear to be as follows: firstly that the provision of work environments can be planned to take particular account of attributes which on the basis of previous research (Warr, 1987) have been shown to be related to positive mental health. Secondly that the operation of such work environments needs to be carefully monitored to ensure that an individual worker is not entering an 'additional decrement' relationship with a particular environmental attribute. Thirdly that the structure of work organisation which appears to give the most positive benefit while minimising the risk of 'additional decrement' is that of the 'co-operative small business'.
Systematic investigation of the precise relationship that operates between environmental attributes and mental health will require the development of standard measures of both work environments and workrelated psychological functioning. On the basis of the above descriptive accounts one would predict changes in dimensions of self-esteem, perceived mastery and social interaction skills in workers in a co-operative work project environment compared to those in a traditional psychiatric rehabilitation workshop environment.

The projects are presented here as trial attempts at providing meaningful work designed to facilitate the development of self confidence and present real life opportunities for the development of social skills. The creation of these more therapeutic work environments has involved staff in giving a higher priority to conditions that facilitate the growth of self confidence whilst also developing a refined sensitivity to the limits of each individual.

\section{Acknowledgements}

Many thanks to Geoff Shepherd for his helpful comments on an earlier draft of this paper.

\section{References}

Beard, J. H., Propst, R. N. \& Malamud, T. J. (1982) The Fountain House model of psychiatric rehabilitation. Psychosocial Rehabilitation Journal, 5, 47-53.

BENNETT, D. H. (1970) The value of work in psychiatric rehabilitation. Social Psychiatry, 4, 224-230.

LA Rocco, J. M. \& Jones, A. P. (1978) Co-worker and leader support as moderators of stress strain relationships in work situations. Journal of Applied Psychology. 63, 629-634.

LeFF, J. P. \& Vaughn, C. E. (1985) Patterns of response in high EE and low EE relatives of psychiatric patients. In Expressed Emotion in Families: Its Significance for Mental illness (eds. C. E. Vaughn \& J. P. Leff). New York: Guildford Press.

Pilling, S. (1988) Work and the continuing care client. In Community Care in Practice (eds. A. Lavender \& F. Holloway). Chichester: John Wiley.

SHEPHERD, G. (1984) Institutional Care and Rehabilitation. London: Longmans.

(1989) The value of work in the 1980s. Psychiatric Bulletin, 13, 231-233.

Strauss, J. S., Rakfeldt, J., Harding, C. M. \& Liberman, P. (1989) Psychological and social aspects of negative symptoms. British Journal of Psychiatry, 155 (suppl. 7), 128-132.

WARR, P. (1987) Work, Unemployment and Mental Health. Oxford University Press.

Wing, J. K. \& Brown, G. W. (1970) Institutionalism and Schizophrenia. Cambridge University Press. 